\title{
Is diagnosing exposed dentine a suitable tool for grading erosive loss?
}

\author{
W. Peter Holbrook • Carolina Ganss
}

Received: 4 July 2007 / Accepted: 17 December 2007 / Published online: 29 January 2008

(C) Springer-Verlag 2007

\begin{abstract}
Quantifying tooth wear in general and erosion in particular mostly is made by distinguishing between lesions restricted to enamel and lesions reaching the underlying dentine. Various scores for grading have been used, but in all systems, higher scores are given in cases of exposed dentine, thus, indicating a more severe stage of the condition. Clinical diagnosis of exposed dentine is made by assessing changes in colour or optical properties of the hard tissues. This paper aims to review the literature and discuss critically problems arising form this approach. It appears that classifying the severity of erosion by the area or depth of exposed dentine is difficult and poorly reproducible, and taking into account the variation of enamel thickness, the amount of tissue lost often is not related simply to the area of exposed dentine. There has still been very little longitudinal investigation of the significance of exposed dentine as a prognostic indicator. Further work and discussion is needed to reevaluate the explanative power of current grading procedures.
\end{abstract}

Keywords Tooth erosion · Tooth wear · Dentine

\section{Introduction}

This review illustrates the problems that clinicians and researchers have experienced in quantifying tooth erosion.

W. P. Holbrook $(\bowtie)$

Faculty of Odontology, University of Iceland,

Reykjavík, Iceland

e-mail: phol@hi.is

C. Ganss

Department of Operative and Preventive Dentistry, Dental Clinic, Justus Liebig University,

Giessen, Germany
Assessing the degree of erosion in an individual may be difficult [32], but is important, as it reflects net exposure to the erosive forces and the opposing forces of protection, for example from saliva. Grading erosion present plays a part in the assessment of the problem, the need for treatment and, potentially, may indicate means for prevention of further tooth wear. If a reliable method for assessing the loss in vivo of tooth substance were available, then it might be possible to determine if erosion was continuing or had been halted, for example by preventive actions. Whilst some assessment of enamel erosion might be possible by assessing the progressive loss of anatomical contour, this is more difficult when erosion has reached the dentine. The diagnosis of exposed dentine is made by assessing changes in colour [43] or changes in the optical properties of the hard tissues, the validity of which, however, has not yet been investigated.

This paper will consider the following main points:

- Does dentine exposure correlate with the severity of erosion?

- Can dentine exposure be reliably and reproducibly diagnosed?

- What is the interplay of factors causing tooth wear and how can other forms of tooth wear be distinguished from erosion when the wear has reached dentine?

- Are the parameters used for grading tooth erosion applicable to both the primary and secondary dentitions?

- Could symptoms of dentine hypersensitivity assist in the grading of erosive loss?

Does dentine exposure correlate with the severity of erosion?

For grading, the overwhelming majority of tooth wear and erosion indices use the differentiation between lesions 
restricted to enamel and lesions reaching the underlying dentine. The rationale for linking severity of erosion to extension into dentine probably stems from experience with dental caries and restorative procedures, but has not yet been critically discussed. It is an interesting question whether the progression of erosion from enamel into dentine has any significance in terms of disease, although it may well have a bearing in terms of treatment and, sometimes, the presence of symptoms of hypersensitivity felt by the patient.

One of the most widely used indices for assessing tooth erosion is that of Lussi et al. [30], albeit sometimes modified [6]. This index does indeed attempt to grade the severity of erosion by assessing the degree of dentine exposure in a simple and, presumably reproducible, way as shown in Table 1. As can be seen, grades 2 and 3 record increased severity of erosion on facial surfaces by judging the area of exposed dentine, rather than loss of dentine. On other surfaces, grade 2 requires the involvement of dentine.

Other indices use thirds of the affected surface with exposed dentine as thresholds $[13,35,41]$ or score the severity of lesions using a more detailed grading with respect to depth of the lesion, as enamel loss only as code 1 or 2, loss of enamel with exposure of dentine with the enamel dentine junction (EDJ) visible as code 3, loss of enamel and dentine beyond EDJ as code 4 and loss of enamel and dentine with exposure of pulp as code 5 [36]. Despite variations in the definition of scores, all indices give higher scores when dentine is exposed, thus, indicating a more severe stage of the condition.

This suggests that the amount of tissue loss must be higher when dentine is exposed than when enamel coverage is still present. When considering the thickness of enamel, however, it is obvious that this is not always the case. Enamel gradually thickens from the cervical region occlusally. At the coronal third of the crown, the enamel thickness is about $1.5 \mathrm{~mm}$, in the cervical third, about $0.5 \mathrm{~mm}$ and becomes increasingly thinner towards the enamel cementum junction [26]. Thus, when the entire smooth surface of a tooth is exposed to acid, the dentine will be first exposed in the cervical region. At the occlusal area, enamel is thickest at the functional cusps, in upper molars. In lower molars, however, the enamel is thinnest at the mesiobuccal cusp, and is progressively thicker in order from the mesiolingual and distolingual to the distobuccal cusp tips [26]. This would explain the finding that lower first molars, particularly the mesio-buccal cusp tip, is the region where exposed dentine occurs most often. Taking into account the gross variation in enamel thickness, it is not surprising that the correlation between exposed dentine and the severity of wear is weak.

A comparison of the amount of tissue loss assessed visually and histological findings revealed that the percentage of teeth with exposed dentine was high even in cases with minor substance loss and, in contrast, that enamel can be present in teeth with moderate to severe substance loss. Furthermore, dentine was exposed in all cases of cupping or grooving even if only minor substance loss occurred [17]. Similar results have been found in a study investigating primary teeth [5]. This showed that in 31 teeth with visually diagnosed wear, only three had enamel present histologically, and even in one of ten teeth in which no wear was diagnosed visually, the histological examination revealed exposed dentine.

Once dentine is exposed, it is more prone than enamel to abrasion $[25,21]$ since its microhardness is much lower than that of enamel [33]. When the severity of lesions is defined by the degree of exposure of dentine, the severity score could assume that tooth wear will progress more rapidly in the future. However, this has not been proven in incidence studies. The predictive value of a diagnosis of exposed dentine to future dental erosion or other forms of tooth wear is far from clear, and longitudinal studies are urgently needed to determine the progression, particularly of erosion, at different sites in the dentition.

Can dentine exposure be reliably and reproducibly diagnosed?

Cupping of the cusp tips on molar teeth is one of the most common presentations of erosion, for example in teenagers (Fig. 1). This has been found in a recent epidemiological
Table 1 Use of the Lussi Index for grading the severity of dentine loss (in bold text)

\begin{tabular}{ll}
\hline Index Score & Observation \\
\hline Facial surfaces & No erosion, glazed appearance, absence of developmental ridges possible \\
0 & Loss of surface enamel, dentine not involved \\
1 & Erosion into dentine $\mathbf{5 0 \%}$ of affected surface \\
$\mathbf{2}$ & Erosion into dentine $\mathbf{5 0 \%}$ of affected surface \\
$\mathbf{3}$ & No erosion, glazed appearance, absence of developmental ridges possible \\
Other surfaces & Slight erosion, rounded cusps, restorations stand proud of enamel, no dentine erosion \\
0 & Severe erosion, more pronounced than score $\mathbf{1}$, dentine involved \\
1 & \\
$\mathbf{2}$ &
\end{tabular}




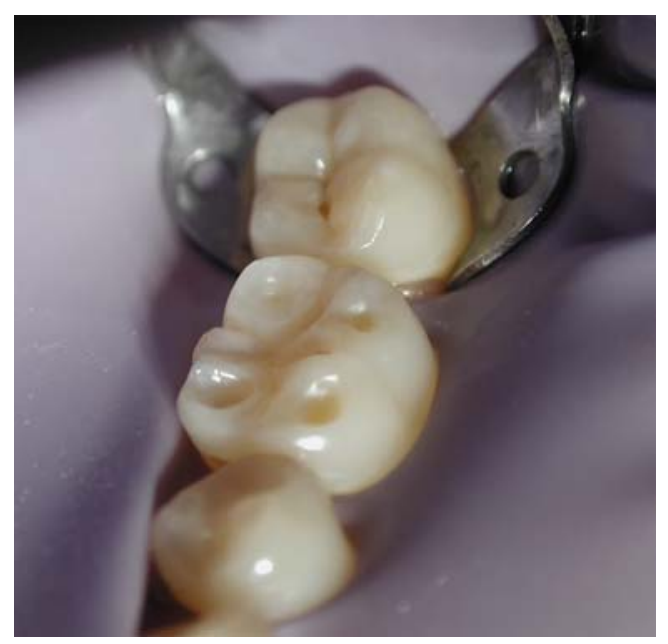

Fig. 1 Cupping of the cusp tips on the molar teeth is an early sign of erosion where extension of erosion into dentine is difficult to determine

study of erosion in Iceland [6] and was also reported in other studies [16, 30, 42].

One major problem in assessing the degree of erosion in cupping is whether or not the dentine has been exposed at the base of the lesion. Because labial and palatal enamel surfaces have a greater surface area, the observer better appreciates their surface anatomy than with a narrow cuplike lesion formed into a tooth cusp tip. Thus, grading the severity of cuppings is more difficult than perhaps it is for labial and palatal surfaces.

Ganss et al. [17] demonstrated that when compared with histological examination, only $65 \%$ of areas with exposed dentine, $88 \%$ of areas with enamel present and $67 \%$ of all areas examined had been diagnosed correctly. Clinicians demonstrated relatively poor reliability and reproducibility in their diagnosis of dentine exposure regardless of their professional experience.

Al Malik et al. [5] have also shown that while grading erosion from visual and photographic records gave comparable scores, the degree of erosion was underestimated compared with the degree of tooth wear determined histologically. One way to increase the reliability of indices is to keep the grading scheme simple because minor differences in severity are difficult to assess, at least with the naked eye. For example, in a study from van Rijkom et al. [43], two scores for enamel and dentine tissue loss each were used scoring slight enamel wear as 1 , deep enamel wear as 2, wear into dentine as 3 and wear into dentine for more than one half of smooth surfaces as 4, and the Kappa values achieved were low. Larsen et al. [28], in contrast, attempted a prevalence study of tooth erosion using seven examiners and only three clear criteria defining grade 1 as erosion limited to the enamel, erosion exposing the dentine less than $50 \%$ of the area of the surface as 2 and erosion exposing dentine in more than $50 \%$ of the surface as 3 .
Despite a careful calibration, including a thorough discussion of the criteria and the experience gained during the study, substantial inter-examiner differences in diagnosis were found. On the other hand, a good strength of agreement was achieved with an index proposed by Larsen et al. [27] where five scores for incisal/occlusal surfaces were used.

Further investigations specifically aimed at assessing the reliability and reproducibility of scoring the involvement of dentine in the grading of erosion is necessary, should this criterion be included a clinical index of erosion. One future perspective could be the development of instrument-supported approaches. A recent report of optical techniques involving nitrogen-laser-induced fluorescence [42] appeared to offer the possibility of differentiating accurately between erosion into enamel and into dentine. This method may, according to the authors, even be applicable in vivo, although the reported studies were in vitro.

What is the interplay of factors causing tooth wear and how can other forms of tooth wear be distinguished from erosion when the wear has reached dentine?

Factors leading to tooth wear, including erosive agents, such as dietary and gastric acid interact with protective factors from the diet, oral hygiene procedures and, particularly, saliva. Interestingly, one study of the relationship between erosion, soft drink consumption and reflux disease found the consumption of Coca-Cola ${ }^{\circledR}$ three times per week to be the dominant factor in the development of molar erosion [24], but the interplay of factors is often complex. Although the net outcome of erosive and reparative factors does not necessarily have to be tooth wear, it appears that once tooth wear has started, the interaction of these factors becomes ever more complex, not least by the time tooth wear has reached the dentine. Thus, the interplay of physical and chemical factors and the relevance of this to dentine wear will be considered together.

Relevant physical forces are attrition and abrasion either from mastication or from oral hygiene procedures. Frequent exposure to dietary or gastric acid will lead to a softening of the dental hard tissues, making it easier for forces of attrition and abrasion to contribute significantly to the overall wear on the teeth. Whilst the effects of acids on enamel are relatively simple, leading to the dissolution of mineral and surface softening, the results on dentine are more complex. Chronic exposure to acids not only leads to an increasing loss of mineral but also to a progressive exposure of the organic dentine matrix, the effects of which, however, are not well known.

The most investigated interplay between erosion and physical forces is the abrasive effect of toothbrushing. An increased wear of eroded enamel and dentine was demon- 
strated in a number of studies [7-9, 14, 21, 38, 45], even if one study did not prove this effect for dentine [18]. Azzopardi et al. [11] have also shown that a combination of erosion and abrasion causes more tooth wear than either tooth wear force on its own. Results of epidemiological studies are ambiguous in demonstrating only weak [2,29] or no $[3,37,39]$ association between the occurrence of erosion and oral hygiene habits.

With respect to abrasion from mastication, the occlusal surfaces are at particular risk. When dentine is exposed, abrasive foods and oral hygiene products tend to hollow out softer surface regions [31]. This can take place when an abrasive diet is consumed or in cases of acid-weakened dental tissues where a less abrasive bolus could also have similar effects. Clinically, the shape of occlusal lesions can be remarkably similar, making the diagnosis of the predominant aetiological factor difficult to determine.

Perhaps commonest among these non-erosive factors contributing to tooth wear is attrition [12]. There is little information about the relative prevalence of facets in relation to different aetiological factors for wear and their progression when dentine is reached. It appears, however, that attrition tends to be superimposed on abrasion in cases of abrasive diet, as facets seldom occur in ancient remains and are not more prevalent in subjects with acidic diet when compared to subjects with an average western diet [15].

The problems of measuring tooth erosion in an individual presenting with tooth wear as shown in Figs. 2, 3 and 4 are considerable, as not only is it difficult to envisage how much dentine and enamel has been lost but it is also increasingly difficult to attribute the loss of tissue to one particular aetiological factor or another as the tooth wear progresses. Even in clear cases of acid erosion, there may be a combination of intrinsic and extrinsic acid contributing to the clinical appearance.

Are the parameters used for grading tooth erosion applicable to both the primary and secondary dentitions?

One particularly difficult problem is assessing tooth wear in the deciduous dentition where the tooth structure withstands the forces of tooth wear somewhat less than the permanent dentition. An example is shown in Fig. 5 of a case where the aetiology of considerable erosion was never clear even when it continued into the permanent dentition. Indices used for the permanent dentition have also been used in the primary dentition [3, 35], but also, a special index for children has also been developed [36].

The prevalence of erosive wear in the deciduous dentition varies between 6 and $100 \%$, and the percentage of children with erosion into dentine varies between 1 and $50 \%[4,10,20,23,46]$. The high prevalence of erosive wear in the deciduous dentition is remarkable when the short period in function is considered, but could be explained by the softer nature of the primary tooth substance leading to increased wear from physical impacts. The susceptibility to acids, in contrast, is probably not greater than for primary than for permanent dental tissues [22]. The enamel of deciduous teeth, however, is much thinner than that of permanent teeth [19], which will lead to the rapid exposure of dentine. These factors will tend to make scores greater for deciduous teeth, and the links with known aetiological factors seem less clear. Studies using the same criteria for the primary and permanent dentition revealed higher prevalence data for the primary than for the permanent dentition when lesions involving dentine are regarded $[3,35]$. It is unclear if these data really reflect more severe tissue loss occurring in children or if the thin deciduous enamel leads to early exposure of dentine also in cases of minor wear, which would mean an overestimation of the condition.

Perhaps the more relevant question is whether tooth erosion in the deciduous dentition is a prognostic indicator of likely erosion in the permanent dentition, as was the case in the subject illustrated in Fig. 5. Meurman and ten Cate [34] have pointed out that there were no longitudinal clinical studies of progression of erosion in the deciduous teeth nor does the continuing of erosion into the permanent dentition appear to have received wide attention. In the last decade, only one study has demonstrated an increased risk of erosion in the permanent dentition when erosion had been present in the primary dentition. As study models were used, the relevance of exposed dentine was, however, not assessed [16].

Fig. 2 Clinical case to illustrate the difficulties of attributing diagnosis of tooth wear. This example of severe tooth wear was thought to be attrition, superimposed on erosion, of the occlusal surfaces of posterior teeth and palatal surfaces of maxillary teeth

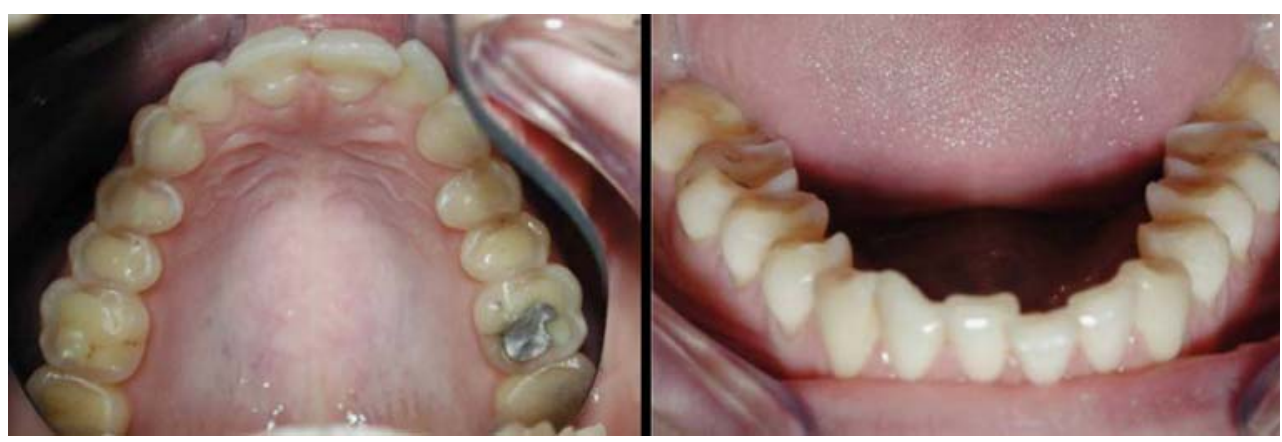




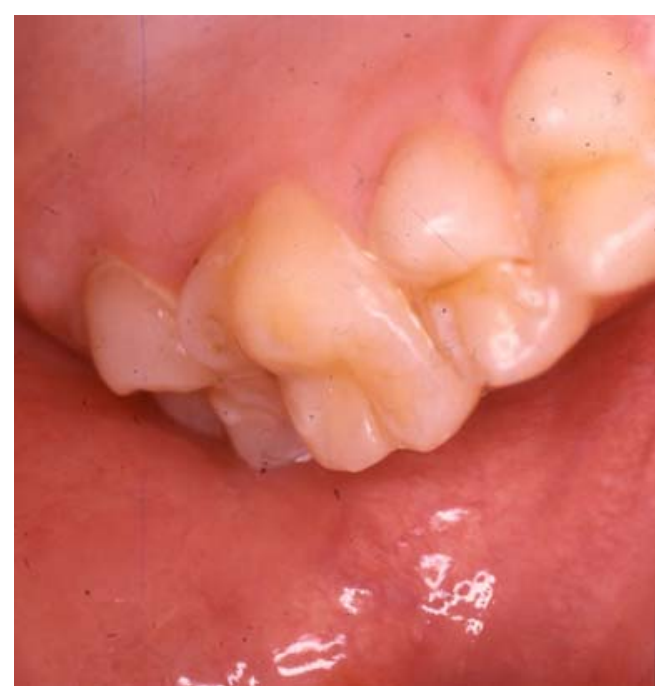

Fig. 3 Erosion of the palatal cusps of maxillary molar and premolar teeth in a patient with gastro-oesophageal reflux disease. Note that dentine is visible on the mesio-palatal cusp of the first molar tooth

Identifying the cause of erosion in the deciduous dentition may enable preventive measures, or treatment in the case of reflux disease, that could eliminate the risk of erosion in the permanent dentition. The UK National Guidelines in Paediatric Dentistry [40] notes the importance of recording the probable aetiological factors but notes specifically the unsuitability of the Smith and Knight Index [41] for measuring small longitudinal changes in tooth erosion and the problems of the complex interaction of causative and protective factors that make tooth erosion a more complex diagnostic and prognostic problem than would perhaps be thought initially to be the case.

\section{Could symptoms of dentine hypersensitivity assist} in the grading of erosive loss?

Once tooth wear has extended into dentine, there is a possibility that the patient will experience symptoms of hypersensitivity [44]. There are numerous causes of dentine hypersensitivity and, therefore, great care is needed in diagnosing hypersensitivity as a result of tooth erosion reaching dentine. The mechanisms underlying hypersensitivity [44] strongly suggest that exposure of dentine tubules to the mouth will cause hypersensitivity in some, but not all, subjects. Consequently, the presence of symptoms of dentine hypersensitivity in a patient with signs of tooth erosion is strongly suggestive of extension of the erosion into dentine. While acidic drinks may expose the dentine tubules and remove early plaque formed on the dentine, thus leading to the symptoms of hypersensitivity, other factors such as toothbrushing may also contribute to this [1].

In conclusion, distinctions are commonly made between erosion into enamel and erosion into dentine. Methods of scoring are derived from parameters associated more with

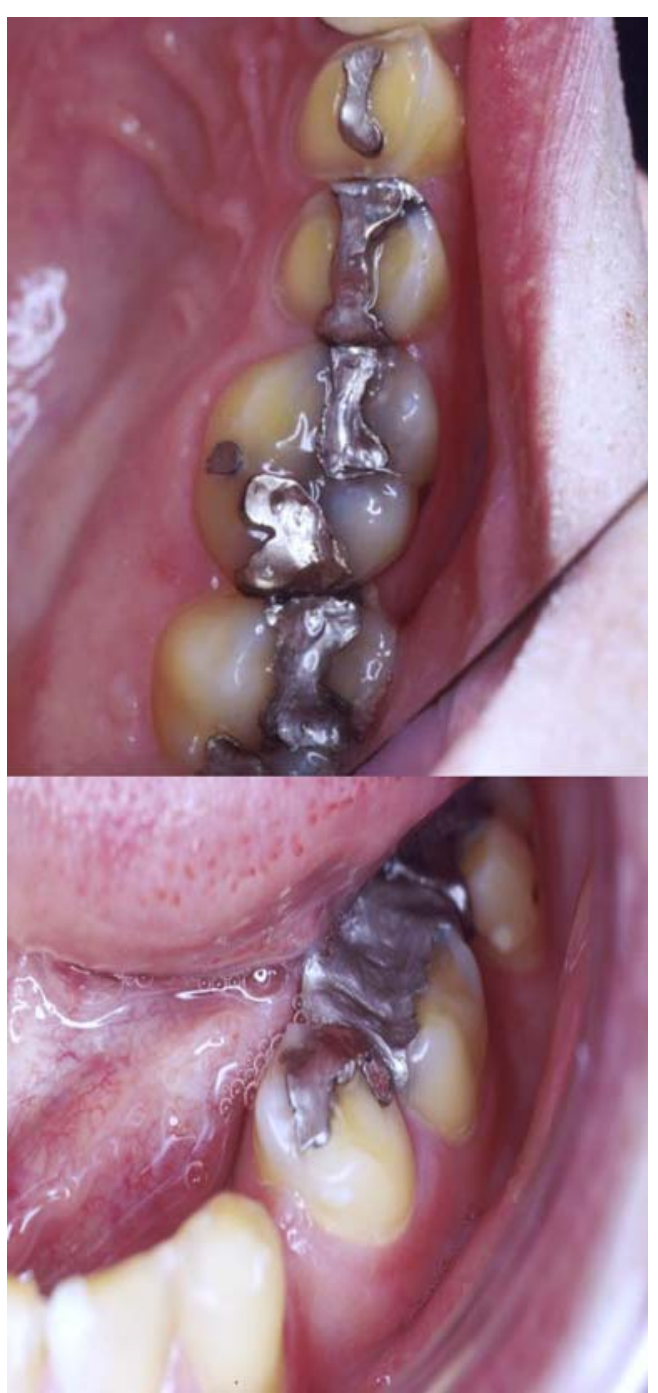

Fig. 4 Typical appearance of erosion in a patient with gastrooesophageal reflux disease showing palatal erosion of the maxillary tooth cusps and buccal erosion of the mandibular tooth cusps. The degree of tooth wear and the presence of restorations make grading difficult

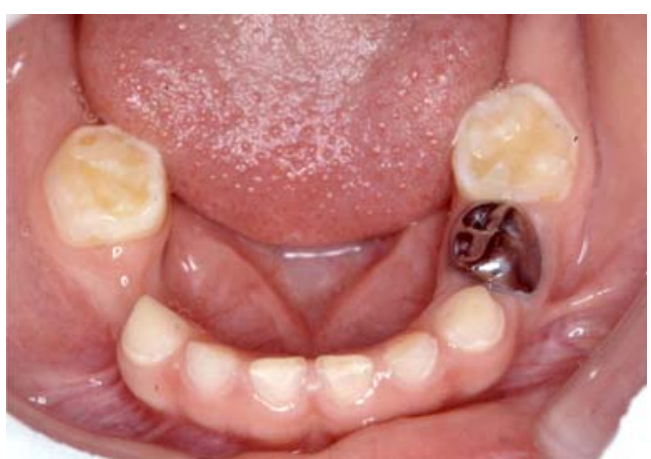

Fig. 5 Clinical appearance of severe erosion, probably combined with other forms of tooth wear, in the deciduous dentition of a patient in whom no pathological reflux disease was recorded. The reported diet was relatively normal but erosion later appeared in the first permanent molar teeth 
dental caries and restorative procedures for that disease rather than specifically for tooth wear. The interplay of tooth wear factors is complex and requires further research. Classifying the severity of erosion by the area or depth of exposed dentine is difficult and poorly reproducible and, particularly with respect to the variation of enamel thickness, the amount of tissue lost often is not related to dentine exposure. There has still been very little longitudinal investigation of the significance of exposed dentine as a prognostic indicator. Further work is needed to reevaluate the explanative power of current grading procedures.

Conflict of interest statement The authors confirm that they have no conflict of interest with respect to the material presented in this paper.

\section{References}

1. Addy M (2006) Tooth brushing, tooth wear and dentine hypersensitivity-are they associated? J Ir Dent Assoc 51:226-231

2. Al-Dlaigan YH, Shaw L, Smith AJ (2002) Dental erosion in a group of British 14-year-old, school children. Part III: Influence of oral hygiene practises. Br Dent J 192:526-530

3. Al-Majed I, Maguire A, Murray JJ (2002) Risk factors for dental erosion in 5-6 year old and 12-14 year old boys in Saudi Arabia. Community Dent Oral Epidemiol 30:38-46

4. Al-Malik MI, Holt RD, Bedi R (2002) Erosion, caries and rampant caries in preschool children in Jeddah, Saudi Arabia. Community Dent Oral Epidemiol 30:16-23

5. Al-Malik MI, Holt RD, Bedi R, Speight PM (2001) Investigation of an index to measure tooth wear in primary teeth. J Dent 29:103-107

6. Arnadottir IB, Saemundsson SR, Holbrook WP (2003) Dental erosion in Icelandic teenagers in relation to dietary and lifestyle factors. Acta Odontol Scand 61:25-28

7. Attin T, Buchalla W, Gollner M, Hellwig E (2000) Use of variable remineralization periods to improve the abrasion resistance of previously eroded enamel. Caries Res 34:48-52

8. Attin T, Koidl U, Buchalla W, Schaller HG, Kielbassa AM, Hellwig E (1997) Correlation of microhardness and wear in differently eroded bovine dental enamel. Arch Oral Biol 42:243-250

9. Attin T, Siegel S, Buchalla W, Lennon MA, Hannig C, Becker K (2004) Brushing abrasion of softened and remineralised dentin: an in situ study. Caries Res 38:62-66

10. Ayers KM, Drummond BK, Thomson WM, Kieser JA (2002) Risk indicators for tooth wear in New Zealand school children. Int Dent J 52:41-46

11. Azzopardi A, Bartlett DW, Watson TF, Sherriff M (2001) The measurement and prevention of erosion and abrasion. J Dent 29:395-400

12. Bartlett D, Smith BGN (2000) Definition, classification and clinical assessment of attrition, erosion and abrasion of enamel and dentine. In: Addy M, Embery G, Edgar WM, Orchardson R (eds) Tooth wear and sensitivity. Martin Dunitz Ltd, London, pp 87-92

13. Eccles JD (1979) Dental erosion of nonindustrial origin. A clinical survey and classification. J Prosthet Dent 42:649-653

14. Eisenburger M, Shellis RP, Addy M (2003) Comparative study of wear of enamel induced by alternating and simultaneous combinations of abrasion and erosion in vitro. Caries Res 37:450-455

15. Ganss C, Klimek J, Borkowski N (2002) Characteristics of tooth wear in relation to different nutritional patterns including contemporary and medieval subjects. Eur J Oral Sci 110:54-60
16. Ganss C, Klimek J, Giese K (2001) Dental erosion in children and adolescents - a cross-sectional and longitudinal investigation using study models. Community Dent Oral Epidemiol 29:264-271

17. Ganss C, Klimek J, Lussi A (2006) Accuracy and consistency of the visual diagnosis of exposed dentine on worn occlusal/incisal surfaces. Caries Res 40:208-212

18. Ganss C, Schlueter N, Hardt M, von Hinckeldey J, Klimek J (2007) Effects of toothbrushing on eroded dentine. Eur J Oral Sci $115: 390-396$

19. Grine FE (2005) Enamel thickness of deciduous and permanent molars in modern Homo sapiens. Am J Phys Anthropol 126:1431

20. Harding MA, Whelton H, O'Mullane DM, Cronin M (2003) Dental erosion in 5-year-old Irish school children and associated factors: a pilot study. Community Dent Health 20:165-170

21. Hooper S, West NX, Pickles MJ, Joiner A, Newcombe RG, Addy $M$ (2003) Investigation of erosion and abrasion on enamel and dentine: a model in situ using toothpastes of different abrasivity. $\mathrm{J}$ Clin Periodontol 30:802-808

22. Jaeggi T, Lussi A (2006) Dental erosion in children. Monogr Oral Sci 20:140-151

23. Jaeggi T, Lussi A (2004) Erosionen bei Kindern im frühen Schulalter. Schweiz Monatsschr Zahnmed 114:876-881

24. Jensdóttir T, Arnadottir IB, Thorsdottir I, Bardow A, Gudmundsson K, Theodors A, Holbrook WP (2004) Relationship between dental erosion, soft drink consumption, and gastroesophageal reflux among Icelanders. Clin Oral Invest 8:91-96

25. Koczorowski R, Wloch S (1999) Evaluation of wear of selected prosthetic materials in contact with enamel and dentin. J Prosthet Dent 81:453-459

26. Kono RT, Suwa G, Tanijiri T (2002) A three-dimensional analysis of enamel distribution patterns in human permanent first molars. Arch Oral Biol 47:867-875

27. Larsen IB, Westergaard J, Stoltze K, Gyntelberg F, Holmstrup P (2000) A clinical index for evaluating and monitoring dental erosion. Community Dent Oral Epidemiol 28:211-217

28. Larsen MJ, Poulsen S, Hansen I (2005) Erosion of the teeth: prevalence and distribution in a group of Danish school children. Eur J Paediatr Dent 6:44-47

29. Lussi A, Schaffner M (2000) Progression of and risk factors for dental erosion and wedge-shaped defects over a 6-year period. Caries Res 34:182-187

30. Lussi A, Schaffner M, Hotz P, Suter P (1991) Dental erosion in a population of Swiss adults. Community Dent Oral Epidemiol 19:286-290

31. Mair LH (2000) Wear in the mouth: the tribological dimension. In: Addy M, Embery G, Edgar WM, Orchardson R (eds) Tooth wear and sensitivity. Clinical advances in restorative dentistry. Martin Dunitz Ltd, London, pp 181-188

32. Maupomé G, Ray JM (2000) Structured review of enamel erosion literature (1980-1998): a critical appraisal of experimental, clinical and review publications. Oral Dis 6:197-207

33. Meredith N, Sherriff M, Setchell DJ, Swanson SA (1996) Measurement of the microhardness and Young's modulus of human enamel and dentine using an indentation technique. Arch Oral Biol 41:539-545

34. Meurman JH, ten Cate JM (1996) Pathogenesis and modifying factors of dental erosion. Eur J Oral Sci 104:199-206

35. Nunn JH, Gordon PH, Morris AJ, Pine CM, Walker A (2003) Dental erosion-changing prevalence? A review of British National childrens' surveys. Int J Paediatr Dent 13:98-105

36. O'Sullivan EA (2000) A new index for the measurement of erosion in children. Eur J Paediatr Dent 1:69-74

37. Öhrn R, Angmar-Månsson B (2000) Oral status of 35 subjects with eating disorders - a 1-year study. Eur J Oral Sci 108:275-280 
38. Ponduri S, Macdonald E, Addy M (2005) A study in vitro of the combined effects of soft drinks and tooth brushing with fluoride toothpaste on the wear of dentine. Int J Dent Hyg 3:7-12

39. Rytömaa I, Järvinen V, Kanerva R, Heinonen OP (1998) Bulimia and tooth erosion. Acta Odontol Scand 56:36-40

40. Shaw L, O'Sullivan E (2000) UK National Clinical Guidelines in Paediatric Dentistry. Diagnosis and prevention of dental erosion in children. Int J Paediatr Dent 10:356-365

41. Smith BG, Knight JK (1984) An index for measuring the wear of teeth. Br Dent J 156:435-438

42. Thomas SS, Mallia RJ, Subhash N (2007) Investigation of in vitro dental erosion by optical techniques. Lasers Med Sci (in press) DOI $10.1007 / \mathrm{s} 10103-007-0489-\mathrm{Z}$
43. van Rijkom HM, Truin GJ, Frencken JE, Konig KG, van't Hof MA, Bronkhorst EM, Roeters FJ (2002) Prevalence, distribution and background variables of smooth-bordered tooth wear in teenagers in the Hague, the Netherlands. Caries Res 36:147-154

44. West NX (2006) Dentine hypersensitivity. Monogr Oral Sci 20:173-189

45. Wiegand A, Lemmrich F, Attin T (2006) Influence of rotatingoscillating, sonic and ultrasonic action of power toothbrushes on abrasion of sound and eroded dentine. J Clin Periodont Res 41:221-227

46. Wiegand A, Müller J, Werner C, Attin T (2006) Prevalence of erosive tooth wear and associated risk factors in 2-7-year-old German kindergarten children. Oral Dis 2:117-124 